\title{
ОПРЕДЕЛЕНИЕ СУЩНОСТИ СОЦИАЛЬНОЙ БЕЗОПАСНОСТИ РЕГИОНА
}

\author{
(c) 2021 Жогова Елена Вячеславовна \\ кандидат экономических наук, Высшая инженерно-экономическая школа \\ Санкт-Петербургский политехнический университет Петра Великого, Россия, Санкт-Петербург \\ E-mail: zhogova_188@mail.ru \\ (c) 2021 Карпенко Павел Алексеевич \\ соискатель, Высшая инженерно-экономическая школа \\ Санкт-Петербургский политехнический университет Петра Великого, Россия, Санкт-Петербург
}

В условиях реализации положений Концепции устойчивого развития регионов и попыток поднятия уровня жизни граждан страны, актуальным является вопрос достижения высокого уровня социальной безопасности населения. По своей сути социальная безопасность является универсальным фактором, влияющим как на устойчивое развитие страны в целом, так и на развитие региона в частности. Более того исследованиями установлено, что экономическая и социальная сферы могут успешно развиваться синхронно, даже при условии наличия проблем в экономической сфере. Дополнительно, система социальной безопасности и программы социальной защиты населения регионов обеспечивает стабильность данного развития. Однако, следует заметить, что при определении результативности социальных программ и концепций следует учитывать помимо показателей, демонстрирующих высокий уровень жизни населения еще и социальные факторы, такие как преступность, количество случаев суицида, наличие терактов и прочего вида социальные потрясения, так как именно данные факторы могут свидетельствовать о реальной результативности программ социальной поддержки. Если число социальных конфликтов в регионе высоко и велико число суицидов и прочих неурядиц в обществе, то следует обратить особое внимание на перечень тех социальных программ и мер социальной поддержки, которые реализуются, и оценить достаточны ли они для населения. Более того достаточно эффективным средством будет являться опрос населения об угрозах социального характера, которые их заботят и оценка общего психологического климата региона.

Ключевые слова: социальная безопасность, регион, устойчивое развитие, социальное обеспечение, угрозы

В условиях реализации положений Концепции устойчивого развития регионов и попыток поднятия уровня жизни граждан страны, актуальным является вопрос достижения высокого уровня социальной безопасности населения. Это сопряжено с тем, что внешнее благополучие регионов не всегда является страховкой от социальных потрясений [1].

Согласно зарубежным исследованиям социальная безопасность названа фундаментальным человеческим правом [2]. Более того разработка программ и систем социальной защиты названа одним из самых значительных достижений социальной политики двадцатого века.

Система социального обеспечения и защиты граждан имеет под собой значительную основу, первоначальное ее упоминание произошло во Всемирной декларации прав человека в 1948 году [2]. Однако развитие данных систем и про- грамм до сих пор сталкиваются со значительным числом проблем.

По своей сути социальная безопасность является универсальным фактором, влияющим как на устойчивое развитие страны в целом, так и на развитие региона в частности.

Более того исследованиями установлено, что экономическая и социальная сферы могут успешно развиваться синхронно, даже при условии наличия проблем в экономической сфере, так как многие европейские страны начали развивать систему социальной безопасности еще на ранней стадии своего развития. Более того было выявлено, что развитая система социальной безопасности обеспечивает и усиливает долгосрочное социально-экономическое развитие.

Согласно Международной конференции труда была принята новая стратегия (2011г.) международной организации труда в области 
социального обеспечения, в которой закреплен двумерный подход к всеобъемлющей системе социального обеспечения: 1. Создание набора основных гарантий социального обеспечения горизонтальное измерение, 2. Расширение круга и скорости охвата социального обеспечения для большего объема людей - вертикальный аспект.

Кульминацией описанной выше концепции являются Рекомендации о минимальных уров- нях социальной защиты [3] (no 202), что стало важным шагом по заполнению пробелов в национальном законодательстве по вопросам социального обеспечения и помощи странам в вопросах нищеты и заботе об уязвимых слоях населения [4].

Основополагающие принципы в рамках $\mathrm{Pe}$ комендаций [3] показаны на рисунке 1.

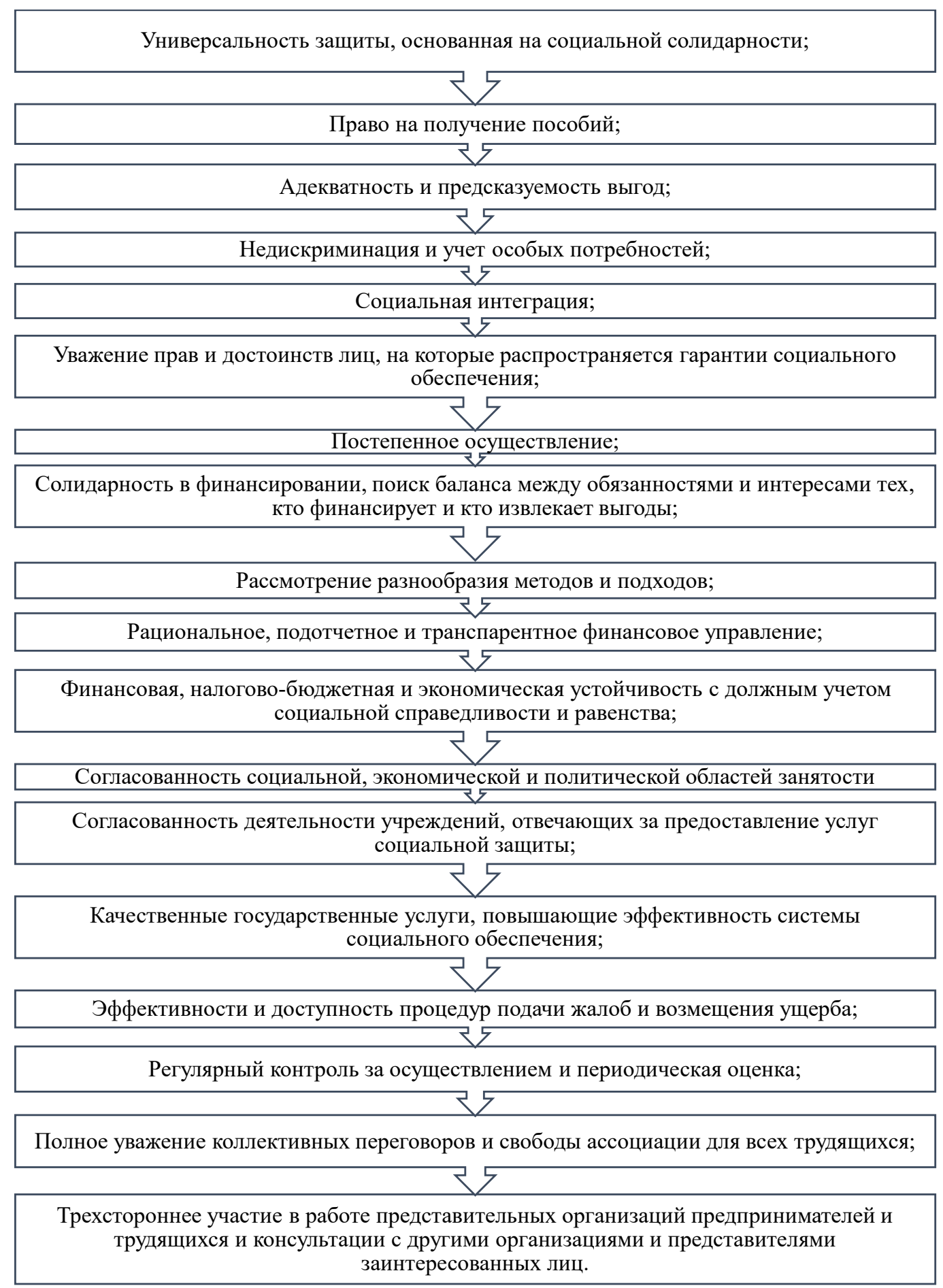

Рисунок 1. Принципы обеспечения социальной безопасности [3] 
Дополнительно в Рекомендациях [3] описаны минимальные меры социальной защиты населения, которые базируются на минимальный уровень социального обеспечения и гарантий, предоставляемых населению. Ключевыми моментами здесь является обеспечение социальной безопасности на протяжении всей жизни индивида, а именно беспрепятственного предоставления медицинских услуг и обеспечения, минимального установленного законодательством базового доход для приобретения доступа к продуктам, товарам и услугам первой необходимости. Дополнительно данным документом установлен минимальный перечень гарантий социального обеспечения (рис. 2).

Также следует заметить, что текст Рекомендаций уделяет внимание необходимости применения профилактических и пропагандистских мер при распространении и реализации социальных льгот и услуг.

Приведенные выше базовые принципы и установки для формирования социальной безопасности населения страны могут с легкостью быть перенесены на региональный уровень.

Далее следует остановиться на том, что подразумевается под «социальной безопасностью» с точки зрения терминологии.

Одни источники говорят о тождественности понятия социальной безопасности и социальным обеспечением, в рамках данного подхода: «Социальная безопасность - это законодательно установленная или закреплённая любым другим механизмом программа социальной защиты, обеспечивающая отдельным категориям граждан (нетрудоспособным, пенсионерам, инвалидам и т.д.) гарантированный уровень дохода» [2].

Согласно данным Международной ассоциации социального обеспечения, наиболее распространение формы социальной защиты это - социальное страхование или/и социальная помощь, универсальные программы, источники финансирования в данном случае роли не играют, ими могут быть резервные фонды, рыночные структуры, государственное финансирование.

В отчете о социальной безопасности «Social Security Programs Throughout the World» [5] (2018) посвящённом вопросам распространения социальной безопасности по всему миру, под «социальной защитой понимаются законодательно установленные программы страхования физических лиц от возможной потери дохода и возможности его заработать, и расходов возникающих в связи с рождением (в том числе и беременностью и родами), смертью и браком» [5]. Данное понятие подразумевает предоставление социальной безопасности как для застрахованного лица, так и для иждивенцев.

Механизмы социальной безопасности позволяют вернуть утраченный доход или его часть гражданину, при условии наличия сложных жизненных ситуаций (инвалидность, старость, болезнь, материнство и т.д.). Данный отчет подразумевает два вида социальной поддержки в виде денежных выплат (программа поддержания дохода) и пособия в натуральной форме (предоставление услуг) и три широких подхода к

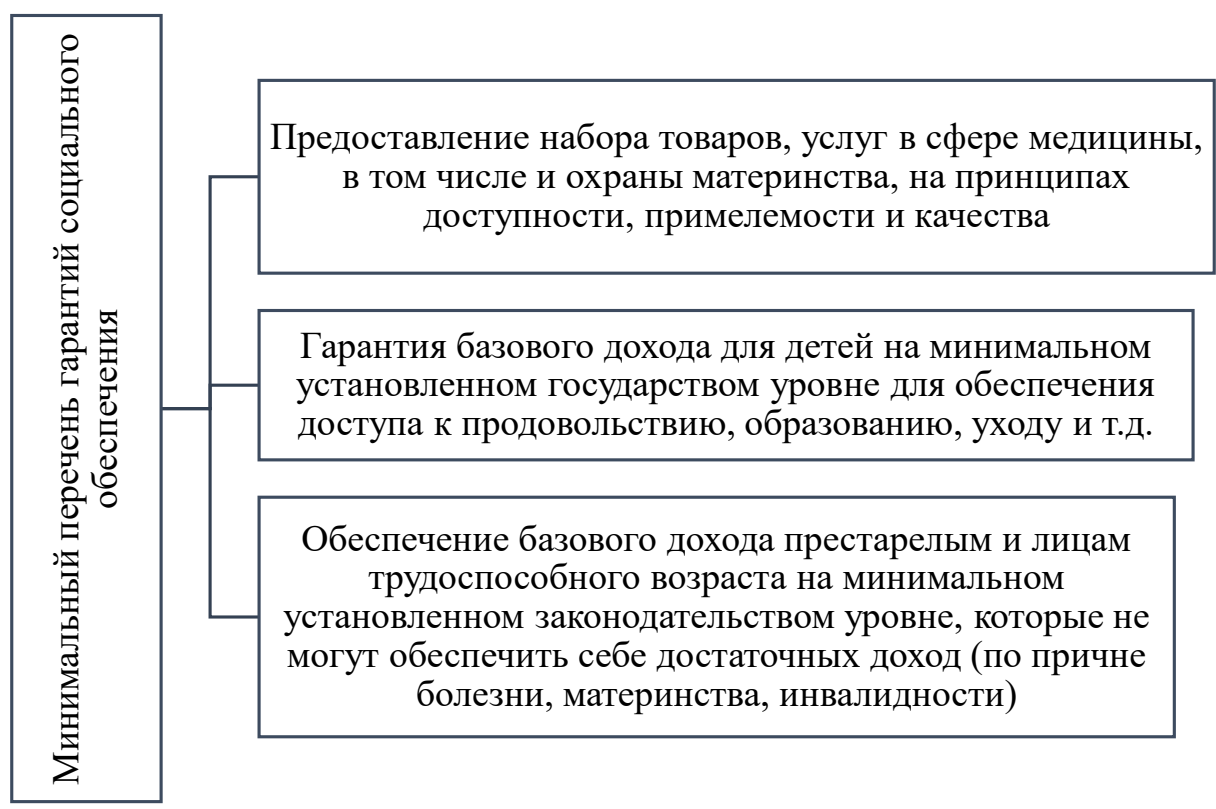

Рисунок 2. Минимальный перечень гарантий социального обеспечения [3] 
программам поддерживания минимального дохода, а именно системы, связанные с занятостью (employment-related), универсальные (universal) и проверенные (means-tested) [5].

Программы универсальные и связанные с занятостью подразумевают поддержку застрахованных лиц, иждивенцев, пособие по потере кормильца. Программы, основанные на проверенных подходах, подразумевают поддержку малоимущих, чей доход ниже прожиточного минимума. Данный перечень программ не является исчерпывающим и может разница в зависимости от страны.

Для перехода на региональный уровень стоит привести понятие социальной безопасности региона и обратить внимание на исследование Кулик А. М., Стрябкова Д.В., Диденко П.А. «Социальная безопасность как элемент экономической безопасности региона» в котором «социальная безопасность региона - это состояние защищенности жизненно важных для общества и личности интересов и потребностей от различных угроз как внутри, так и вне региона» [6]. Согласно этого же исследования задачами социальной безопасности является «формирование условий, обеспечивающих стабильное, прогрессирующее развитие социальных отношений, сохранение, укрепление и обогащение бытия, то есть защищенности качественного состояния социальных отношений, обеспечивающих прогрессирующее развитие личности, общества и государства» [6].

Социальная безопасность на региональном уровне подвергается воздействию со стороны следующих факторов (угроз): неэффективность региональной политики, ухудшающаяся демографическая ситуация, ухудшение среды обитания и условий жизнедеятельности, несовершенство системы здравоохранения, наличие национальных и межэтнических противоречий, политический экстремизм, терроризм. Влияние того или иного набора факторов может усиливаться или снижаться в зависимости от законотворческой деятельности региона, проводимой региональной политики и экономической обстановки, так как у каждого региона есть своя доля независимости в данных аспектах. Однако, дополнительным преимуществом в борьбе с приведенными угрозами является возможность решения данных проблем не только на региональном и местном уровнях, но и с использованием ресурсов федерального уровня [7].
Дополнительно в рамках исследования Кулик А. М., Стрябкова Д.В., Диденко П.А. «Социальная безопасность как элемент экономической безопасности региона» [6] для регионального уровня выбран определенный перечень показателей характеризующий уровень экономической безопасности региона: размер прожиточного минимума; среднедушевой доход населения; среднемесячная номинальная заработная плата работников предприятий; ожидаемая продолжительность жизни; численность населения с доходом ниже прожиточного уровня.

В исследовании Гайфуллина А.Ю., Гайфуллиной М. М. «Методический подход к оценке социальной безопасности региона» [8] социальная безопасность выступает в качестве «социальных отношений, предоставляющих любому индивиду возможности реализовывать свой внутренний потенциал, находясь вне угрозы экономический, социальной и физической деградации, даже в условиях снижения уровня и качества жизни».

Здесь важными факторами влияющими на уровень социальной безопасности названы укрупненные блоки индексов, а именно: демографические (демографическая нагрузка, прирост населения, продолжительность жизни, миграция), факторы рынка труда (численность активного населения, занятость, безработица), благосостояние и социальная защита(соотношение разного рода доходов и прожиточного минимума, площадь жилых помещений на одного жителя), правопорядок (уровень преступности и категории), здравоохранение (обеспеченность мед. услугами, заболеваемость), образование и духовно-культурное развитие.

В исследовании Даниловой 3.А. «Социальная безопасность региона: уровень угроз и тревожности населения» [9] приведено достаточно большое количество определений социальной безопасности, но мы приведем наиболее нас заинтересовавшее: «Социальная безопасность это защищенность социальной сферы общества и государства от угроз, способных разрушить ее или обусловить ее деградацию» [9]. В рамках данного исследования социальная безопасность базируется на социальных гарантиях государства, упреждающих и превентивных мерах по снижению рисков.

В рамках данного исследования приводится описание классификации социальной безопасности, а именно: исходя их субъектов угроз: 
общая, групповая, индивидуальная; исходя из источника угрозы: публичная, частная; дополнительно градация может проводиться по месту потенциальной реализации угрозы. Для определения факторов, влияющих на социальную безопасность региона, проведено анкетирование экспертов и первостепенными названы: макроэкономическая нестабильность (рост инфляции), рост базовых затрат (ЖКХ, электричество, стоимость товаров первой необходимости), рост цен, уровень преступности и криминализации общества, коррупция государственных органов. Чуть менее релевантные факторы: разрушение института брака и семьи, низкий уровень жизни и дохода населения.

Результаты исследования [9] являются наиболее интересными для нас так как при оценке уровня социальной безопасности региона было задействовано анкетирование, то есть своеобразное ранжирование по рейтингу влияния факторов региона, мы считаем это эффективным направлением для оценки релевантности, так как данный подход доказал свою эффективность в качестве работы рейтинговых агентств в экономике, более того здесь мы видим, что размер дохода на который делается упор при оценке устойчивого развития региона занимает не первое место при оценки удовлетворенностью социальной безопасностью населения. Более того в исследовании сделан уклон на психологические факторы, влияющие на население и достаточно актуально замечено, что «запас прочности» индивида, противостоять негативным явлениям сокращается в условиях довлеющего положения угроз внешней среды, влияние которых усиливается в условия несовершенства реализуемой политики государственными структурами региона [10].

В заключении следует сказать, что реализация Концепции устойчивого развития регионов, несомненно, является значимым и позитивным направлением развития. Дополнительно, система социальной безопасности и программы социальной защиты населения регионов обеспечивает стабильность данного развития. Однако, следует заметить, что при определении результативности социальных программ и концепций следует учитывать помимо показателей, демонстрирующих высокий уровня жизни населения еще и социальные факторы, такие как преступность, количество случаев суицида, наличие терактов и прочего вида социальных потрясении, так как именно данные факторы могут свидетельствовать о реальной результативности программ социальной поддержки. Если число социальных конфликтов в регионе высоко и велико число суицидов и прочих неурядиц в обществе, то следует обратить особое внимание на перечень тех социальных программ и мер социальной поддержки, которые реализуются, и оценить достаточны ли они для населения. Так как социальные неурядицы могут возникать при недостаточности социальных мер защиты (не всем уязвимым категориям граждан доступны меры социальной защиты) или при нереалистичности установления минимального предела (возмещаемый доход не позволяет в полной мере приобретать жизненно необходимые лекарства и продукты) каждому региону необходимо индивидуализировать свой подход к поддержанию уровня социальной безопасности на высоком уровне.

Дополнительно всегда остается открытым вопрос каков должен быть перечень социальноэкономических показателей, имеющий сильную взаимосвязь с уровнем экономической безопасности, всегда остается ощущение, что либо не все факторы учтены, или что часть факторов существенно влияющих на экономическую безопасность региона просто остаются без внимания, такие как психологические характеристики населения.

\section{Библиографический список}

1. Родионов Д.Г., Баранова И.В., Насрутдинов М.Н. Идентификация ключевых медиаторов развития социального потенциала региона // Российский экономический интернет-журнал. Открытое акционерное общество Институт исследования товародвижения и ..., 2019. № 3. Р. 69.

2. Social. security: A fundamental human right. UNDERSTANDING SOCIAL SECURITY. [Electronic resource]. URL: https://ww1.issa.int/about/socialsecurity.

3. Рекомендация. R202 - Рекомендация о минимальных социальных защитах, 2012 (No 202) (ilo.org) [Electronic resource]. URL: https://www.ilo.org/dyn/normlex/fr/f?p=NORMLEXPUB:12100:0:: NO:: P12100_INSTRUMENT_ ID:3065524. 
4. Hagemejer., R. McKinnon, Роль национальных минимальных уровней социальной защиты в распространении социального обеспечения на всех (Le rôle des socles nationaux de protection sociale dans l'extension de la sécurité sociale à tous) - Hagemejer - 2013 - Международный.

5. Программы. социального обеспечения Во всем мире: Европа, 2018 [Electronic resource]. URL: https://clck.ru/ Y3JmE.

6. Кулик А.М., Стрябкова Д.В., Диденко П.А. «Социальная безопасность как элемент экономической безопасности региона с. 195-200.

7. Родионов Д.Г., Баранова И. В., Насрутдинов М.Н. Формирование модели интерферирования показателей социального потенциала региона // Российский экономический интернет-журнал. Открытое акционерное общество Институт исследования товародвижения и ..., 2019. № 4. Р. 119.

8. Гайфуллин А.Ю., Гайфуллина М.M. «Методический подход к оценке социальной безопасности региона». Экономические науки. Фундаментальные исследования. № 12, 2015. С.1001-1006.

9. Данилова 3.А. «Социальная безопасность региона: уровень угроз и тревожности населения» Современные исследования социальных проблем (электронный научный журнал) № 5(49), 2015 с.746.

10. Родионов Д.Г., Кудрявцева Т. Ю. Механизм и принципы формирования кластерной промышленной политики // Инновации. Общество с ограниченной ответственностью» Трансфер-Инновации», 2018. № 10. Р. 81-87. 